\title{
Representação dos alunos e professora acerca do valor educativo do Modelo de Educação Desportiva numa unidade didática de Atletismo
}

\author{
Representations of the students and their teacher about the educational \\ value of Sport Education Model within an Athletic unit
}

Isabel Mesquita ${ }^{*}$, José Augusto Rodrigues Pereira², Rui Araújoํㅜ, Cláudio Farias ${ }^{1}$, Ramiro Rolim ${ }^{1}$

\begin{abstract}
Este estudo teve como propósito examinar as perceções de uma professora de Educação Física e dos seus alunos em relação ao valor educativo do Modelo de Educação Desportiva, no desenvolvimento da competência motora, da literacia desportiva e do entusiasmo. O estudo foi aplicado numa unidade de Atletismo tendo participado uma professora com 19 anos de experiência em ensino e uma turma com 19 alunos do $6 .^{\circ}$ ano de escolaridade. No final da unidade foram realizadas entrevistas semiestruturadas a todos os participantes. O clima envolvente das tarefas de aprendizagem e o contexto de ensino autêntico e significativo foram percebidas como determinantes no desenvolvimento dos alunos enquanto desportistas competentes, literatos e entusiastas. A competência adquirida foi percebida como resultado do tempo mais longo concedido à unidade em relação às unidades mais tradicionais, bem como da autonomia crescente dos alunos na realização das tarefas, fruto do equilíbrio gerado entre inclusão e competição, o qual também promoveu a literacia desportiva. O entusiasmo resultou da interdependência das dinâmicas de trabalho cooperativo, da festividade fomentada pelo modelo e do clima motivacional gerado, com impacto substantivo no compromisso dos alunos para com a prática. Finalmente, a implementação do Modelo de Educação Desportiva ofereceu à docente um espaço de reflexão e desenvolvimento profissional.

Palavras-chave: Atletismo, Abordagem de Ensino centrada no aluno, Modelo de Educação Desportiva, Competência, Literacia, Entusiasmo.
\end{abstract}

RESUMO This study examined the perceptions of a physical education teacher and her students about the educational value of Sport Educational Model regarding the development of competence, literacy and enthusiasm. The study was applied through an athletics unit in 6th grade class and taught by a teacher with 19-years of experience. The participants' perceptions were captured through semi-structured interviews, which were administered at the end of the unit. All interviews were transcribed verbatim. Data analysis comprised the logical-semantic interpretation of the most prominent ideas. The inductive and the constant comparison methods were used to categorize the data. The task-involving climate and the authentic and meaningful learning context emerging were critical in the development of competent, literate and enthusiastic sportspersons. Competence was perceived as the result of a longer duration unit regarding traditional units and the sense growing of autonomy, promoted by the balance between competition and inclusion, which also promoted literacy. The enthusiasm was fostered by the interrelationship between the dynamics in cooperative work and the motivational climate generated having significant impact on students' engagement in practice. The implementation of the Sport Education model opened a window for reflection and professional development to the teacher.

Keywords: Athletics, Student-centred teaching approach, Sport Education, Competence, Literacy, Enthusiasm.

\author{
Artigo recebido a 22.07.2014; Aceite a 07.02.2015 \\ ${ }^{1}$ Faculdade de Desporto da Universidade do Porto, FADE-UP, Porto, Portugal \\ ${ }^{2}$ Faculdade de Educação Física e Desportos da Universidade Federal de Juiz de Fora, UFJF, Juiz de Fora, \\ Brasil \\ * Autor correspondente: FADE-UP, R. Dr. Plácido da Costa 91, 4200-450 Porto. E-mail: imesquita@fade.up.pt
}




\section{INTRODUÇÃO}

A necessidade de se implementarem modelos de ensino que coloquem o aluno no centro do processo de aprendizagem, tem vindo a ganhar corpo e substância na reforma educativa encetada a partir do início dos anos noventa do século passado (Dyson, Griffin, \& Hastie, 2004; Mesquita, Farias, \& Hastie, 2012; Mesquita, Graça, Gomes, \& Cruz, 2005). Esta perspetiva, comumente designada de abordagem centrada no aluno, enfatiza o trabalho em grupo dos alunos para atingirem objetivos comuns, contando com o professor enquanto agente facilitador da aprendizagem, e onde a valorização dos processos cognitivos dos alunos, da tomada de decisão e da compreensão das situações-problema constitui o mote para o seu desenvolvimento pessoal, social e desportivo (Mesquita, 2012, 2013; Mesquita et al., 2012).

O valor da interação com os outros (pares e alguém "mais capaz") na edificação das aprendizagens, respaldado pelos ideais sócioconstrutivistas entra, assim, no novo século como uma via de formação prioritária. No âmbito da Educação Física (EF) os ideais sócioconstrutivistas encontram eco no Modelo de Educação Desportiva (MED) (Siedentop, 1994), o qual se filia, por sua vez, no Modelo de Aprendizagem Cooperativa (Slavin, 1995). O MED prioriza estratégias de ensino implícitas e informais no processo de ensino-aprendizagem, quando comparado com outros modelos tradicionais (fundados na abordagem centrada no professor) (Metzler, 2005) como é o caso do Modelo de Instrução Direta (Mesquita \& Graça, 2009). Estas estratégias de ensino mais implícitas e informais conferem ao aluno protagonismo central nas decisões relacionadas com o processo de aprendizagem, nomeadamente na interpretação da sua atividade cognitiva e motora, comprometendo-o e responsabilizando-o pelas decisões/ações correntes nos cenários de aprendizagem, em suma, incentivando-o a aprender de forma deliberadamente autónoma, comprometida e responsável (Mesquita et al., 2012). Indubitavelmente, o MED plasma uma abordagem de ensino centrada no aluno, ao considerá-lo como alguém ativo e responsável pelas suas experiências de aprendizagem e pela construção de redes de significado e conhecimento (Perkins, 1999).

O MED teve a sua génese nos EUA concebido por Daryl Siedentop (1994), o qual sentiu necessidade de colocar a educação lúdica (play education) em destaque nas orientações curriculares da disciplina de EF. Tal decorreu do facto dos alunos considerarem fastidiosas as aulas de EF devido ao ensino ser superficial, desportivamente descontextualizado e de caráter generalista (consequentemente, os alunos não aprendiam realmente as habilidades motoras e apenas as afloravam), para além das atividades serem desprovidas de caráter lúdico e competitivo (Graça \& Mesquita, 2009). Em contrapartida, o MED valoriza o conteúdo de ensino porquanto este tem como horizonte o que de mais identitário existe na cultura desportiva, nomeadamente a tradicional unidade didática é transformada numa época desportiva (18-20 aulas), durante a qual os alunos trabalham em equipa (com diferentes funções), onde é incentivada a afiliação a uma equipa, onde a competição formal assume uma posição central ao longo de todo o processo, onde o registo dos recordes é uma constante e todo o processo é rodeado de festividade. Não obstante a competição ser o eixo estruturante de toda a atividade, o MED acautela os fatores de equidade e inclusão, o que significa que aposta na democratização e humanização do Desporto renegando o elitismo e a iniquidade (Curnow \& Macdonald, 1995) e desfazendo, por essa via, falsos equívocos entre o desporto e a Educação Física (Mesquita, 2012).

Mais ainda, este modelo procura a formação holística do aluno, através de três vetores essenciais: a formação de alunos desportivamente competentes (desenvolvimento das habilidades específicas da modalidade), desportivamente literatos (aquisição dos valores e rituais associados à modalidade) e desportivamente entusiastas (incentivando nos alunos a atração pela prática desportiva e a defesa dos valores do Desporto) (Siedentop, 1994).

Relativamente à investigação centrada na perceção de professores e alunos sobre o desenvolvimento de experiências pedagógicas em 
unidades de MED, esta tem demonstrado o reconhecimento de ambos os atores no elevado impacto educacional deste modelo, nomeadamente na aprendizagem (Browne, Carlson, \& Hastie, 2004; Hastie \& Sinelnikov, 2006), no desenvolvimento pessoal e social dos alunos (Grant, 1992; Pill, 2008), nas suas atitudes (Hastie \& Sinelnikov, 2006; MacPhail, Gorely, Kirk, \& Kinchin, 2008) e valores (Bennet \& Hastie, 1997; O’Donovan, 2003). Todavia, esta investigação tem sido quase exclusivamente focada nos desportos de equipa, tais como o Futebol, o Basquetebol e o Voleibol (Hastie, Martinez de Ojeda, \& Calderón, 2011). Até ao momento, apesar de seguirem a mesma linha de resultados, poucos estudos têm centrado a sua atenção em desportos individuais (Coelho, Farias, Santos, Rolim, \& Mesquita, 2012; Hastie, Calderón, Rolim, \& Guarino, 2013; Hastie, Sinelnikov, \& Guarino, 2009; Hastie, Sluder, Buchanan, \& Wadsworth, 2009; Pereira, Mesquita, Araújo \& Rolim, 2013). No caso particular do atletismo, Coelho, Farias, Santos, Rolim, e Mesquita (2012) examinaram as perceções de uma professora e dos seus alunos sobre as dificuldades percebidas e as estratégias pedagógicas implementadas durante a primeira experiência de aplicação do MED. Os relatos sistemáticos da professora (diário reflexivo e diário da unidade didática) bem como as entrevistas semi-estruturadas realizadas aos alunos, revelaram um desajustamento inicial do planeamento das tarefas ao ritmo de resposta dos alunos e uma tendência em centralizar os processos de ensino. O elevado conhecimento pedagógico do conteúdo por parte da professora e as estratégias de ensino implementadas permitiram o ajustamento da dinâmica, estrutura e conteúdo das tarefas aos seus objetivos e, concomitantemente, uma participação mais ativa dos alunos na construção das aprendizagens. Por seu turno, Hastie, Calderón, Rolim, e Guarino (2013) e Pereira, Mesquita, Araújo, e Rolim (2012) avaliaram o impacto do MED e do Modelo de Instrução Direta nas aprendizagens de elementos técnicos do Atletismo. Apesar de ambos os grupos mostrarem melhorias significativas nas aprendizagens, os alunos que participaram na unidade de MED obtiveram maiores progressos.

O estudo de experiências formativas de professores e alunos em unidades de MED tornase, assim, crucial em modalidades individuais, como é o caso particular do Atletismo. De facto, a natureza das modalidades individuais poderá não fomentar implicitamente aspetos-chave do desenvolvimento pessoal e social do aluno, como sendo a cooperação, a entreajuda e o sentido de pertença a um grupo, ao contrário do que acontece com os desportos coletivos e, concomitantemente, não ofertar cenários de práticas incitadoras do desenvolvimento social. No MED, a prática extensiva em equipas e o alto comprometimento dos alunos para atingirem objetivos comuns, oferecem condições favoráveis à cooperação entre eles e, consequentemente, geram maiores oportunidades de aprendizagem (Siedentop, Hastie, \& Van der Mars, 2011). Em particular, no caso do Atletismo, o qual requer a aprendizagem de habilidades técnicas de forma minuciosa, dada a implicação da performance técnica na obtenção de sucesso, a aplicação do MED pode constituir uma mais-valia, pelo trabalho cooperativo dos alunos em pequenos grupos, nos quais estes são monitorizados de perto pelos colegas de equipa e pelo professor.

Apesar da investigação centrada nas perceções de professores e alunos durante a participação em unidades de MED ser, de algum modo, extensa, esta carece, ainda, da compreensão do modo como as principais metas do MED são operacionalizadas na prática pelo professor. Em concomitância, importa examinar as perceções dos alunos em relação à vivência do MED tendo por referência os eixos pedagógicos e estruturais que o norteiam e configuram. Este conhecimento reveste-se de grande importância, porquanto fornece informação relevante para o refinamento das estratégias pedagógicas no ensino do desporto, e neste caso particular do Atletismo, bem como para a definição e implementação de meios promotores do desenvolvimento pessoal, social e desportivo dos alunos pela vivência do MED.

Neste sentido, o presente estudo pretende examinar as perspetivas de uma professora e dos seus alunos sobre a participação numa unidade 
de Atletismo através do MED, particularmente em relação ao seu valor educativo no que concerne aos três eixos que consubstanciam os objetivos do modelo: a competência motora, a literacia desportiva e o entusiasmo pela prática desportiva.

\section{MÉTODO}

\section{Participantes}

Neste estudo participaram 19 alunos (10 meninas e 9 meninos) com idades compreendidas entre os 11 e os 13 anos, a frequentar o $6^{\circ}$ ano de escolaridade no ano letivo de 2011/2012. Os participantes foram selecionados pelo método de conveniência (Kandola, Banner, O’Keefe-McCarthy \& Jassal, 2014), a partir de três critérios: (1) o professor possuía experiência substancial (19 anos) no ensino da Educação Física nos $2^{\circ}$ e $3^{\circ}$ ciclos do Ensino Básico; (2) a turma pertencia ao Ensino Básico, correspondente ao grau de ensino onde se pretendia aplicar este estudo; (3) o ensino do Atletismo fazia parte do currículo a lecionar nesta turma, no período de recolha de dados.

Previamente à implementação da unidade foi realizada, pelo professor, a avaliação diagnóstica do desempenho motor dos alunos, através da qual se verificou a existência de níveis distintos, embora com uma distribuição relativamente equilibrada (oito alunos de nível de habilidade superior, NHS, e onze de nível de habilidade inferior, NHI).

Uma vez que a professora não apresentava experiência prévia como docente na aplicação do MED, situação recorrente dado ser um modelo de ensino recente, participou numa oficina de formação, teórica e prática, com a duração de 50 horas, durante todo o ano letivo anterior à realização do presente estudo, orientada por dois docentes experientes na lecionação e investigação em modelos de ensino na EF, do Mestrado em Ensino da Educação Física nos Ensinos Básico e Secundário da Faculdade de Desporto da Universidade do Porto. A realização de oficinas de formação que tem como propósito dotar o docente das ferramentas conceptuais necessárias para a compreensão do modelo e, concomitantemente, o implementar devidamente, é apresentada na literatura da especialidade como um procedimento eficaz no acautelar de uma preparação prévia do professor à implementação do MED (Hastie et al. 2013; Pereira et al., 2013). A primeira fase desta formação baseou-se em aulas expositivas onde se debateram os seguintes temas: (1) Modelos e estilos de ensino no contexto da EF; (2) Conceção, propósitos e características do MED; (3) Implementação do MED no ensino do Atletismo na EF e nos JDC; e (4) Investigação no MED: domínios e investigações empíricas. A segunda fase compreendeu uma etapa de natureza prática, na qual os participantes aplicaram diferentes unidades de MED durante todo o ano escolar, orientados pelos formadores desta mesma formação.

O conselho de ética institucional da FADEUP e o conselho executivo da escola onde foi desenvolvida a investigação aprovaram o protocolo de pesquisa. Do mesmo modo, os pais ou os responsáveis legais por cada aluno assinaram a carta de consentimento para permitir a participação dos seus educandos no estudo. $\mathrm{O}$ sigilo e a confidencialidade de todos os participantes foram salvaguardados, sendo os participantes referenciados através de números nos resultados.

\section{Unidade de Atletismo}

A unidade de Atletismo compreendeu 20 aulas (tabela 1), conforme indicado pela literatura (Siedentop et al., 2011) como valor de referência para a aplicação de uma unidade de MED, onde foram incluídas todas as características referidas pela literatura relativa a este modelo (época desportiva, afiliação a uma equipa, competição formal, registo de recordes, festividade e evento culminante) (Siedentop et al., 2011). Nesta unidade, a primeira aula teve como propósito a explicação de todos os processos inerentes ao desenvolvimento de aulas segundo este modelo, assim como também a distribuição dos alunos pelas diferentes equipas. Em função dos resultados obtidos pelos alunos em 3 testes motores (velocidade, lançamento e salto), realizados de forma equitativa $e$ equilibrada em função do desempenho motor dos alunos, avaliado de um teste de desempenho motor, realizado imediatamente antes da 
aplicação da unidade didática. Atendendo à idade dos participantes, as funções a desenvolver pelos alunos na UD atletismo foram: alunostreinadores, estatísticos, juízes de saltos, cronometristas, juízes de partida e de chegada.

Nesta unidade, os alunos participaram numa competição de barreiras, lançamento do peso e triplo-salto, intercalada com a prática dessas mesmas habilidades (Siedentop et al., 2011). Durante as aulas de treino das habilidades, foi conferida oportunidade aos alunos de desempenharem diferentes funções para além de praticantes (estatísticos, juízes de saltos, cronometristas, juízes de partida e de chegada), num ambiente livre de pressão competitiva. Durante as aulas dedicadas ao treino das habilidades, foi dada oportunidade aos alunos de praticarem as outras funções que não as de atletas, num ambiente positivo e livre de pressão. Durante os eventos competitivos, as equipas foram emparelhadas de forma rotacional, alternando entre competição e tarefas de gestão da aula (por exemplo, registo de tempos e medidas), sendo que todos os alunos passaram pelas diferentes funções definidas para esta unidade, à exceção da função de treinador, a qual não foi exercida por todos os alunos. Esta opção encontra respaldo no facto da função de treinador exigir competências de liderança e aceitação pelos pares, as quais, não estando presentes, podem gerar indisciplina no seio do grupo (Mesquita, 2012). Não obstante, a função de treinador foi proporcionalmente distribuída por meninos e meninas, de forma a prevenir desequilíbrios de poder, relacionados com o género e estatuto dos alunos, como retratado em estudos prévios (Hastie, 1998). Mais ainda, os alunos conquistavam bonificações por cumprimento das regras de fair-play, equidade, esforço e comprometimento com as tarefas de gestão.

Tabela 1

Conteúdo da unidade de Atletismo

\begin{tabular}{|c|c|}
\hline 1 & $\begin{array}{l}\text { Introdução à unidade: Constituição das equipas e nomeação dos treinadores. } \\
\text { Testes de habilidades }\end{array}$ \\
\hline 2 & $\begin{array}{l}\text { Professor dirige a aula: habilidades básicas do triplo salto e regulamento. } \\
\text { Alunos treinadores lideram o aquecimento das equipas, supervisionados pelo professor. } \\
\text { Primeira competição da Época Pré-Desportiva. }\end{array}$ \\
\hline $3-7$ & $\begin{array}{l}\text { Alunos-treinadores: aquecimento das equipas supervisionados pelo professor. } \\
\text { Professor dirige a aula: triplo salto, corrida de barreiras (partida e transposição de uma barreira), lançamento de } \\
\text { peso e respetivas regras e regulamentos. } \\
\text { Atribuição de funçôes: repórter, juiz, estatístico, responsável pelo material. }\end{array}$ \\
\hline 8 & $\begin{array}{l}\text { Alunos participam numa competição formal aplicando as regras e assumem diferentes funções: repórter/jornalista, } \\
\text { juiz, estatístico e responsável pelo material. }\end{array}$ \\
\hline 9 & $\begin{array}{l}\text { Aluno-treinador dirige as aulas: habilidades básicas da corrida com barreiras (passagem da barreira e ritmo entre } \\
\text { as barreiras). Funções: atleta, responsável pelo material, árbitro, estatístico. Primeira competição da Época } \\
\text { Desportiva. }\end{array}$ \\
\hline $10-14$ & $\begin{array}{l}\text { Aluno-treinador dirige as aulas: habilidades básicas do triplo salto, corrida com barreiras, lançamento do peso e } \\
\text { respetivos regulamentos técnicos. } \\
\text { Funções: atleta, responsável pelo material, árbitro, estatístico. Competição Época Desportiva. }\end{array}$ \\
\hline 15 & $\begin{array}{l}\text { Aluno-treinador dirige as aulas. Funções: atleta, responsável pelo material, árbitro, estatístico, repórter. } \\
\text { Competição preparatória para o evento culminante. }\end{array}$ \\
\hline $16-18$ & $\begin{array}{l}\text { Aluno-treinador dirige as aulas: Consolidação dos } 3 \text { eventos do atletismo. Funções: atleta, responsável pelo } \\
\text { material, árbitro, estatístico. } \\
\text { Competição da Época Desportiva. }\end{array}$ \\
\hline 19 & Organização e treino para o evento culminante. Época Desportiva \\
\hline 20 & $\begin{array}{l}\text { Evento Culminante: cerimónia de entrega de prémios (medalhas a todos os atletas, equipa campeã, equipa qu } \\
\text { mais evoluiu, atleta que mais evoluiu). }\end{array}$ \\
\hline
\end{tabular}

A preparação dos alunos-treinadores contemplava uma aula extracurricular por semana durante toda a unidade, orientada pela professora da turma, onde estes aprendiam não só os conteúdos relacionados com o Atletismo, mas também estratégias instrucionais, nomeadamente a apresentação de tarefas, a identificação e correção do erro e a gestão da aula. Adicionalmente, além do acompanhamento do docente durante as aulas, estes alunos contaram ainda com algum material didático, como, por exemplo, manuais cartões de exercícios e assistência indireta. 


\section{Recolha de dados}

A realização de entrevistas assumiu-se como a técnica mais adequada ao propósito do estudo, uma vez que permite aceder a conceitos irredutíveis à quantificação, tentando perceber o "porquê" e "como" das questões em detrimento do quanto (Gratton \& Jones, 2004). Foram realizadas duas entrevistas, uma à professora e outra a dez alunos (cinco meninos e cinco meninas), dos 19 participantes que compunham a turma. As entrevistas neste estudo adquiriram um caráter semiestruturado e de resposta aberta, permitindo uma condução mais flexível e ajustada, através da alteração da ordem das questões e da introdução de questões auxiliares, sempre que necessário, para procurar recolher informação mais precisa, autêntica e contextualizada (Gratton \& Jones, 2004). A validade de construção de ambas as entrevistas foi garantida, porquanto a sua construção baseou-se nos postulados do MED, nomeadamente nos seus propósitos e características (Siedentop, 1994). Por sua vez, a validação de conteúdo foi garantida pelo método de peritagem (Silverman, 2000). Dois peritos, doutorados em Pedagogia do Desporto e com experiência relevante no ensino através do MED (mais de cinco anos), validaram o conteúdo das categorias, atestando e garantindo a representatividade e valor em relação aos problemas em estudo. Posteriormente, foi realizado um estudo piloto, no qual as entrevistas foram aplicadas a um outro professor de Educação Física e a três alunos que não faziam parte do estudo no sentido de aferir a objetividade e clareza das questões. Foram realizados pequenos ajustes na redação das perguntas, processo que, após o seu término, permitiu obter as duas entrevistas finais.

A entrevista comportou as seguintes dimensões: a) perceção da professora sobre: (1) valor educativo e pedagógico do MED, (2) vantagens e desvantagens do MED no desenvolvimento da competência desportiva, literacia e entusiasmo desportivo, (3) vantagens e desvantagens no desenvolvimento das funções adstritas ao MED pelos alunos, (4) problemas e dificuldades advindas das experiências de aprendizagem na vivência de cada função; b) perceção dos alunos sobre: (1) vantagens e desvantagem das experiências de aprendizagem com o MED relativamente à competência desportiva, literacia e entusiasmo pela prática (2) vantagens e desvantagens percebidas no desempenho de cada função, (3) problemas percebidos no desempenho de cada função e como foram ou não ultrapassadas, (4) preferência e razão para o desempenho de cada uma das funções no MED, (5) significados construídos pela experiência desportiva do MED na aula de Atletismo (Bennet \& Hastie, 1997).

Todas as entrevistas foram realizadas num ambiente tranquilo e reservado, de forma a assegurar a privacidade e a confiança dos participantes para o aprofundamento das questões. As entrevistas ocorreram durante o ano letivo de 2011/2012 e tiveram uma duração entre os 20 e 25 minutos, com uma duração média de 23 minutos para os alunos e 99 minutos para a professora. As entrevistas foram gravadas por meio de um gravador digital da marca SONY, modelo ICD-P Séries, sendo posteriormente transcritas e processadas para o computador. Para assegurar a fiabilidade das informações, as transcrições foram encaminhadas aos participantes para confirmarem o seu conteúdo.

\section{Análise dos dados}

A análise dos dados foi realizada através da análise de conteúdo de índole indutivo, a qual se abstém de impor teorias ou hipóteses à partida, sendo os conceitos gerados a partir dos dados; ou seja, sem categorias analíticas predefinidas (Elo \& Kyngäs, 2008; Moraes, 1999). A abordagem indutiva é de natureza construtiva e, por isso, toma como ponto de partida os dados, os quais, serão traduzidos em categorias, as quais, pretendem essencialmente informar a teoria, contribuindo para o acervo de conhecimento na área (Elo \& Kyngäs, 2008). O seu objetivo não é, portanto, o de generalizar ou testar hipóteses mas, pelo contrário, construir uma compreensão dos fenômenos investigados. Em conformidade, na análise indutiva, a criação de categorias decorre da abstração do concreto, do esforço em encontrar núcleos de significado, descortinandose os critérios e as propriedades que sustentam a 
decisão de agregar ou separar os pedaços de texto (Elo \& Kyngäs, 2008).

Neste estudo, de forma a garantir a preservação do conteúdo semântico das respostas dos participantes, o discurso oral e a gramaticalidade foram respeitados durante a transcrição das respostas. A criação das categorias foi, assim, obtida pelo método de interpretação lógico-semântico das ideias preponderantes no corpus do texto. Neste processo de classificação foram utilizados os procedimentos de condensação da informação e de sumarizações e síntese, o que permitiu o aprofundamento das perceções dos alunos e da professora na identificação de similaridades e pontos de discordância. Este processo conferiu objetividade e rigor ao processo de classificação (Miles \& Huberman, 1994).

A tabela 2 apresenta as categorias, e correspondentes subcategorias, em referência à perceção dos alunos e da professora sobre a sua experiência educativa na unidade de MED. Para a apresentação dos resultados, selecionou-se um conjunto de excertos das entrevistas a título exemplificativo, no sentido de elucidar as perspetivas dos participantes.

Tabela 2

Grelha de codificação relativa à perceção dos alunos e da professora sobre a sua experiência educativa na unidade de MED

\footnotetext{
1. Valor educativo do MED

1.1. Desenvolvimento de alunos desportivamente competentes

1.2. Desenvolvimento de alunos desportivamente literatos

1.3. Desenvolvimento de alunos desportivamente entusiastas

2. Reflexão da professora sobre o MED

2.1. Potencialidades educativas do MED

2.2. Estratégias para otimizar a implementação e o sucesso do MED.
}

\section{Valor educativo do MED}

Desenvolvimento de alunos desportivamente competentes

O facto da unidade didática apresentar uma maior duração (20 aulas), em relação às unidades tradicionais (oito a dez aulas), foi percebido pela professora como o elemento decisivo para incrementar a aprendizagem dos alunos:
"Não tinha expectativas tão elevadas quanto á aprendizagem dos alunos. Penso que melhoraram muito as suas aprendizagens tanto ao nível motor como em termos de regulamento. Por esta unidade ser mais longa do que as unidades tradicionais, todos os alunos adquiriram vários conhecimentos ao nível do regulamento e ajuizamento dos concursos".

As vantagens do MED em promover a aprendizagem também foi notória nas vozes dos alunos:

"Melhorei as minhas habilidades no Atletismo. Antes fazia várias coisas e nunca era excelente em todas e como nessas aulas só fizemos três modalidades e andamos sempre a repetir, fui melhorando. Por ter mais aulas acho que melhorei" (1, NHS). "Eu não acho que melhorei as minhas habilidades, tenho certeza. Porque acho me esforcei porque conseguia fazer coisas que pensava nunca conseguir" (2, NHI). "No lançamento não sabia tantos detalhes como o peso estar colado no pescoço e muitas das técnicas não percebia disso e passei com todas estas aulas a perceber" (3).

O desenvolvimento da competência motora foi fomentado, segundo os alunos, pela aprendizagem cooperativa instalada nas equipas. A este nível os mesmos realçam o valor do trabalho em equipa no desenvolvimento do gosto pela prática e, concomitantemente, na aprendizagem:

"Gostei muito de participar nestas aulas de Atletismo com maior duração. Antes eu tinha que me esforçar mais para que neste período eu conseguisse melhorar a nota e eu consegui fazer os que meus colegas fazem. E depois esta coisa da equipa eu tentei mais e participei mais e acho que consegui fazer tudo" (2, NHI). "Gostei muito dessas aulas mais longas. Porque o principal é que estávamos radiantes, e depois porque estávamos em equipa e todos reagiram muito bem. Gostei de tudo..." (3, NHS).

A professora evidencia as vantagens inequívocas do trabalho em equipa em promover a aprendizagem, onde o espírito de cooperação e entreajuda esteve presente.

"Neste modelo, o facto da transmissão da matéria ser mediada por alunos tranquiliza os menos competentes e creio que por poderem trabalhar em pequenos grupos dá-lhes mais tempo, respeita o seu tempo. Há ainda a salientar as tarefas que 
desempenharam no grupo que, muitas vezes, não sendo de virtuosismo motor e desportivo foram fundamentais na afirmação do grupo/equipa, e isso deu lhes prestigio e protagonismo".

O papel assumido pelos alunos mais habilidosos em apoiar os colegas menos habilidosos, mostrou ser crucial para que todos sem exceção se sentissem membros da equipa, e, concomitantemente, contribuísse para o desenvolvimento da competência motora e desportiva de todos sem exceção, conforme é sublinhado pela professora:

"Essas diferenças mantiveram-se sempre, só que os alunos mais competentes colocaram os seus conhecimentos ao serviço do grupo e aqui reside o valor educativo deste modelo. $O$ espírito de cooperação passou de conceito a habilidade. $O$ alegrarmo-nos com o êxito do outro foi uma realidade. Houve momentos em que os alunos mais competentes se mostraram admirados com o desempenho dos menos competentes, e satisfeitos porque muito desse sucesso era da sua responsabilidade... tudo isso permitiu a todos evoluírem na aprendizagem do Atletismo".

O incremento da motivação para a aprendizagem através do MED foi percebido pelos alunos. Para tal, contribuiu, em muito, o facto de serem os alunos a desempenharem a função de treinador. Esta orientação é percetível nas palavras dos alunos revelando estes, inclusivamente, que tinham maior facilidade em aprender por ser um colega a ensinar, conforme é evidente no excerto seguinte:

"A princípio parecia estranho ser um colega a ensinar, mas depois fomos nos habituando. Foi muito positivo". "Aprendi com ele e gostei que fosse ele a ensinar. Se fosse outra pessoa, talvez não ensinasse tão bem, sentíamos bem com ele" (1, NHS). "Levei os meus papéis muito a sério porque queria ganhar $(8, N H S)$ ".

Em particular, a capacidade dos colegas em exercerem cabalmente a função de treinador foi sublinhada pelos alunos:

"Eu aprendi muito com o meu treinador e gostei muito que fosse ele a ensinar porque sempre nos ajudou a fazer as coisas e tirou nossas dúvidas e porque eu consegui ganhar a minha primeira medalha graças a ele. Ele ajudou-me a melhorar a ultrapassar as barreiras e mais alguns exercícios que tinha dificuldades no primeiro período e no segundo e com a ajuda dele não tive mais problemas" (2, NHI). "Gostei muito do meu treinador, acho que é simpático e ajuda-nos e apoia-nos quando temos dificuldades. Quando estamos em competição ele chama pelo nosso nome, grita e apoia. Gostei muito de ser ele a ensinar..." $(5, \mathrm{NHI})$.

Por sua vez, os alunos que desempenharam a função de treinador evidenciaram elevado entusiasmo e sentido de responsabilidade pelo seu desempenho, sendo as tarefas adicionais que a mesma exige encaradas como algo particularmente importante:

"Gostaria de ser treinadora e treinar a minha equipa [...] lia o manual do treinador e fazíamos vários exercícios e alongamentos, eu tinha outras sugestôes de atividades (1, NHI)". "Gostei mais de ser treinador porque era uma função mais difícil de desempenhar porque tínhamos que incentivar os colegas a fazer o que nós queríamos e pronto. Gostei porque foi um papel interessante, um papel muito duro e eu gosto de desafios" (9, NHS). "Foi uma experiência única e queria ver o que é que a professora fazia para dar as aulas tão bem assim. Foi muito interessante assumir o papel dela” (9, NHS).

Ademais, a preocupação dos alunos que exerceram as funções de treinador em saberem ensinar, no sentido de permitir aos colegas evolução na aprendizagem, foi evidente nas suas palavras:

"Eu acho que levei a sério porque incentivei os meus colegas e acho que eles melhoraram bastante e acho que a minha equipa está muito bem preparada para ir a nacionais e todos os tipos de jogos. [...] Gostei muito de ensinar aos colegas, acho que eles gostaram e estiveram sempre a corrigir" (6, NHS). "No início acho que não dei muita importância, mas depois comecei a gostar mais, porque comecei a dar as aulas todas e fiquei mais responsável." (10, NHS). "Um colega a ensinar o outro foi bom, às vezes duro porque criticavam o que nós fazíamos, mas eu dizia então façam isso, e eles pensavam um bocado e achavam difícil o que eu estava a fazer" $(9, N H S)$

O resgatar de um aluno com deficiência mental para a vivência das experiências educativas na aula de EF foi percebido por um dos alunos que desempenhou a função de 
treinador como uma gratificação pessoal, para além de ser evidente a sua preocupação em lhe proporcionar experiências substantivas de aprendizagem:

"O JC [portador de Síndrome de Down] tem um problema como todos sabem, ele faz coisas que não quer, mas que o cérebro manda fazer e ele faz. Então eu acompanhei-o e ajudei-o a desenvolver seu papel. Durante os exercícios, incentivei-o para que ele se sentisse capaz e que conseguisse apesar do seu problema, e ele conseguiu. Percebi que ele ficou muito feliz, eu vi logo que comecei a incentivá-lo, ele começou logo todo contente a fazer os exercícios connosco e ele gostou muito, porque no final das aulas eu perguntava-lhe sempre se gostava das aulas e ele dizia que gostava muito da aula porque foi divertido e que gostava muito de tirar fotografias e as outras coisas do papel de jornalista" (2, NHI).

O papel da competição como fator estruturante da auto-superação e, consequentemente, da aprendizagem foi marcadamente assumido pela professora:

"A competição é fundamental. Neste momento os alunos adquirem uma nova consciência, é um momento de síntese. Não são raras as vezes em que os alunos referem que nem sabem como conseguiram desempenhar com sucesso esta ou aquela tarefa". "Eles fazem coisas que pensaram nunca alcançar".

Desenvolvimento de alunos desportivamente literatos

O desempenho de múltiplas funções (por exemplo: árbitro, treinador, estatístico, etc.) contribuiu para a compreensão por parte dos alunos do sentido educativo do Desporto, porquanto ficaram sensibilizados para a necessidade de respeitar os outros, de cooperar com todos em prol do grupo, da importância no respeito e cumprimento das regras de conduta desportiva, entre outros aspetos.

O desenvolvimento da cooperação e o sentido de entreajuda experienciado pelos alunos é evidente nos seguintes excertos:

"O treinador foi bom e esteve sempre a falar: "mais Ana - mais Ana, tu consegues, não deixes mal a tua equipa." (1, NHI). "Foi muito bom pertencer à mesma equipa. A minha era muito boa e tinha um dos melhores alunos, tinha menos raparigas que rapazes, mas foi bom. Durante as aulas o treinador e uma amiga (Rita) ajudaram-me muito" (1, NHI).

$\mathrm{O}$ facto de a equipa ser a mesma ao longo de toda a Unidade Temática foi percebido pelos alunos como crucial ao incrementar o espírito de equipa, de cooperação e da construção da identidade no grupo:

"É bom estar numa mesma equipa, porque acho é que por ter o nosso espírito de equipa. Gostei porque achei mais confortável e trabalhei com as mesmas pessoas e cruzar pensamentos, acho que foi divertido e houve muita ajuda e cooperação entre o grupo" (3, NHS). "Gostei de pertencer sempre à mesma equipa [...] ajudou-me mais a concentrar" (5, NHI). "Gostei de pertencer a uma equipa. Eu acho que houve cooperação e muita participação" (7, NHI).

A professora destacou ainda a importância atribuída ao trabalho em equipa no desenvolvimento do fair-play.

"O fato de tudo o que eles faziam contribuir para os pontos da equipa obrigou-os a um maior empenhamento e espírito de sacrificio, da mesma forma que toda a equipa motivava e entusiasmava os alunos com maior dificuldade a esforçarem-se mais para obterem melhores resultados".

A mais-valia do MED, na equidade de oportunidade, ao permitir a todos os alunos, independentemente do nível de habilidade, a oportunidade de participar e dar o seu melhor é patente na perceção de uma aluno de nível de habilidade relativamente inferior:

"Algumas vezes não me senti à vontade com esse tipo de ensinar, como já falei que eu tenho muita vergonha quando tem muita gente a ver e depois não me esforço muito, mas desta vez esforcei-me muito, foi muito diferente" (5). "Ia para a as aulas com vontade de fazer sempre melhor" (2, NHI).

A importância do desempenho das diferentes funções no incremento da dinâmica de trabalho das equipas, do sentido de responsabilidade e do respeito pelo trabalho de todos emerge de forma contundente nas vozes de dois alunos:

"O nosso capitão também gostou muito de liderar a equipa, as repórteres levaram muito a sério o seu papel, colocaram coisas na internet, e tem também os juízes que arbitraram muito bem, registando os tempos" (6, NHS). "Pertencer á mesma equipa foi 
bom porque fizemos treinos articulados, fomos responsáveis, nunca chegamos atrasados, porque se chegássemos atrasados o treinador dava-nos uma raspada e por isso nunca chegamos" (2, NHI).

Desenvolvimento de alunos desportivamente entusiastas

A panóplia de papéis desempenhados pelos alunos no seio de cada equipa mostrou ser um dos fatores que mais explica a adesão dos alunos às aulas de Atletismo, nomeadamente pelo incremento do entusiasmo, pela participação proativa, comprometida e responsável na busca da prossecução de objetivos concretos e partilhados por todos, como refere a professora:

"Os alunos gostaram bastante da experiência tendo contribuído para que olhassem para a modalidade de atletismo com 'outros olhos'. Referiram que gostariam de experimentar outras funçôes Há alguns que querem passar pela experiência de serem Treinadores/Capitães".

A este respeito um dos alunos acrescenta ainda:

"Gostei de todos os papéis. Fui repórter, jornalista e algumas vezes fui juiz no triplo salto e lançamento do peso e também fui atleta. Uma das coisas que eu menos gosto de fazer, é esforçar-me, é um defeito que eu tenho, mas eu gostei muito dos papéis e acho que os desempenhei bem”. (2, NHI).

Ademais, a proatividade e entusiasmo pela prática é evidente no interesse dos alunos em partilhar todas as atividades desenvolvidas nas aulas, como invoca a professora:

"Os alunos sentiram-se bastante motivados na escolha do lema, na elaboração dos cartazes, na realização de medalhas e materiais para a aula. $O$ facto de tudo o que eles faziam contribuir para os pontos da equipa obrigou-os a um maior empenhamento e espírito de sacrifício, da mesma forma que toda a equipa motivava e entusiasmava os alunos com maior dificuldade a esforçarem-se mais para obterem melhores resultados".

Esta marcante intervenção de todos os alunos nas aulas expressa pela professora é corroborada pelos alunos, quando manifestam o seu envolvimento deliberado e comprometido bem como o entusiasmo colocado nas atividades desenvolvidas:
"Nessas aulas acho que gostei de tudo. Gosto do convívio com os colegas, gosto da maneira como estávamos a desempenhar as nossas funçôes na equipa, mesmo que houvesse algumas discussões entre alguns elementos (5, NHI). "Desempenhei os meus papéis com brincadeira, mas levei a sério. Com brincadeira, com bastante alegria $e$ responsabilidade" (1, NHI).

Neste âmbito, os alunos expressaram também de forma inequívoca o sentido lúdico e de autosuperação promovido pela competição, elementos essenciais para o incremento do entusiasmo pela prática:

"Gostei muito das competiçôes. Foi bom. As aulas antigamente eram mais paradas e agora com isso tínhamos que nos esforçar mais e acho que foi uma coisa boa para aprender e participar" (2, NHI). "Gosto muito de competição, e claro de ganhar medalhas e, à medida que vamos tendo competição, vamos aprendendo, e faço amizades ao competir" (6, NHS). "... achei muito divertido competir uns com os outros e acho que houve muito esforço, e os alunos deram seu melhor" (9, NHS).

Mais ainda, o tédio usualmente decorrente do recurso a outros modelos de ensino que não fomentam a proatividade dos alunos nem $o$ trabalho em equipa segundo a professora não se observou com o recurso ao MED.

"Penso que gostaram bastante, aliás, essa prática em equipa foi a que mais os entusiasmou, e chegou na altura certa, caso contrário teriam começado a ficar cansados das rotinas de trabalho que esta, assim como outra modalidade prolongada no tempo, acarreta".

\section{Reflexão da professora sobre o MED}

Potencialidades educativas do MED

As respostas da professora e dos alunos marcam indiscutivelmente o valor educativo do MED na formação dos alunos, numa perspetiva de formação que sublinha a autonomia, a responsabilidade e o compromisso.

"Este modelo de ensino aponta para uma nova forma de estar na vida, orientada para os valores de uma cidadania civilizada, voltado para os outros, de exigência e rigor pessoal, de que todas as pessoas importam e que todas podem ter um espaço com um grau de importância igual, de antivedetismo enfim para uma organização social e afetiva democrática". "Este modelo de ensino permite 
repensar a forma de ensinar. Dar aulas não é encarado como um momento de transmissão de matéria, mas sim, como um momento de partilha, colaboração, fomentação, aprendizagem, cooperação e receção de conhecimentos e aprendizagens. É criada uma relação de cumplicidade e cooperação com os alunos o que potencia o processo ensino-aprendizagem."

O elevado protagonismo assumido pelos alunos em todas as tarefas da aula, desde a gestão até à instrução, a diversidade de funções desempenhadas por eles, o recurso a estratégias pedagógicas que apelam ao incremento da cooperação e ao dinamismo no seio da aula e, concomitantemente, ao maior envolvimento na aula de EF, são mais-valias expressas nas palavras da professora:

"O fato de os alunos se sentirem parte ativa do processo, contribuiu para que todos se envolvessem muito mais na disciplina, pois sentiam estar a dar um contributo válido para as aulas, dado que poderiam desempenhar outro tipo de tarefas nos quais se sentiam mais á vontade (repórter, juiz, etc.)". "Penso que os alunos aprenderam a matéria e não se limitaram a imitar com mais ou menos virtuosismo, mas compreenderam o porquê das coisas [...] Leram alguns documentos que de outra forma não teriam lido, apesar de estarem ao seu dispor".

Por sua vez, o impacto do MED fez-se sentir, particularmente, numa adesão mais comprometida e deliberada na aula de EF por parte dos alunos que, até então pelo recurso a modelos de instrução tradicionais, centrados no professor, evidenciavam apatia, ausência de interesse em aprender as condutas e os conhecimentos alocados à prática desportiva. A professora explicita de forma incisiva este sentimento:

"Vinha sendo desenvolvido um trabalho de conquista para a EF de alguns deles. Havia muitos elementos do sexo feminino. Foi assustador verificar a falta de literacia motora de algumas e a sua desmotivação. Com a introdução deste modelo posso afirmar que foram resgatadas em definitivo. E a prova-lo está a sua participação no final do ano no Sarau de Encerramento das Atividades letivas, em que não tiveram qualquer problema em se expor num evento onde os corpos e as açôes têm tanta visibilidade".
Estratégias para otimizar a implementação e o sucesso do MED

Apesar do MED ser encarado pela professora como promotor de francas vantagens para otimizar o sucesso na aprendizagem, existem alguns fatores que se tornam particularmente difíceis de serem implementados e que devem ser perscrutados pelos professores. O planeamento é de facto o aspeto mencionado pela professora como mais difícil:

"Numa fase inicial é muito trabalhoso, requer uma disponibilidade que muitas vezes não é compatível com as tarefas que o professor tem na escola. Neste momento as escolas são semelhantes ao serviço de urgência dos hospitais. Tem de se decidir, agir, intervir sem qualquer rede, conscientes de que se houvesse tempo talvez a respostas aos problemas fosse mais eficaz. Ora este modelo requer tempo cronológico e tempo interior".

Em particular a necessidade de preparar os alunos para desempenharem a função de treinadores foi percebida pela professora como um aspeto essencial que não pode ser descurado. Neste sentido, a necessidade de preparar os alunos para desempenharem a função de treinador, tanto no que ela exige como na competência para o seu desempenho, foi uma das grandes preocupações da professora:

"No meu caso e dado que os alunos eram bastante novos, era sempre necessário experimentar com os treinadores o que seria abordado, criando assim uma relação, neste pequeno grupo, de grande cumplicidade". "Aqueles que atuaram nestes papéis [treinadores] passaram a ter uma atitude muito mais generosa em relação aos professores porque perceberam como é difícil captar a atenção dos alunos e o quão desagradável é estarem a falar e os outros, os colegas, a manterem conversas paralelas"

A capacidade dos alunos-treinadores em aprenderem os conteúdos a serem ensinados aos colegas foi uma conquista da professora, como evidenciam os seguintes excertos:

"Tenho a certeza que aprenderam os conceitos, as normas e as regras desta modalidade que ainda não tinha sido lecionada e, portanto, penso que muitos dos conhecimentos aprendidos foram consolidados. Esta forma de ensinar despertou nos alunos uma visão sobre este desporto para o qual 
eles não estavam atentos, até porque descobriram algumas especialidades completamente desconhecidas para alguns deles, como é o caso do Triplo Salto."

Para além disso, a idade relativamente baixa dos alunos foi apontada como um aspeto delicado, a ser considerado no sentido de terem sido desenvolvidas estratégias que resolvessem possíveis dificuldades:

"Pelo facto dos meus alunos serem muito novos pensei que teriam alguma dificuldade em desempenhar o papel de treinadores. Mas como optamos por começar a experimentar antes o que seria transmitido na aula seguinte isso facilitou $o$ processo".

A construção de materiais didáticos que sustentaram a implementação do MED, foi apontado pela professora como o aspeto que requer mais tempo e dedicação, mas é de facto essencial para o sucesso na aplicação do MED, dado conferir maior autonomia aos alunos na aprendizagem:

"Houve foi um investimento muito grande na elaboração de materiais, na constituição de fichas e de documentos. Dado que abordei o MED no $3^{\circ}$ período senti a certa altura uma sobrecarga de trabalho, dado que além destas turmas continuava a ter o meu trabalho normal da escola".

O trabalho de preparação dos alunos, anterior à aplicação da unidade didática, é crucial, sem o qual o este modelo pode estar condenado ao fracasso, conforme reitera a professora:

"Este facto [o sucesso obtido nesta unidade didática] deve-se ao trabalho anterior de treino/exercitação, ao entendimento do movimento e aos elevados níveis de concentração que se mobiliza para o momento da avaliação/competição. Os alunos sentiram-se bastante motivados na escolha do lema, na elaboração dos cartazes, na realização de medalhas e materiais para a aula."

Dada a agenda sofisticada do MED para o estabelecimento das dinâmicas de ensino e aprendizagem operantes na aula, a necessidade de mais tempo para a aula de EF foi também sublinhada pela professora:

" $A$ dificuldade de os alunos preencherem algumas grelhas de observação ou de registo e a falta de tempo no final das aulas principalmente de 45 minutos para preencherem essas fichas devidamente e era necessário fazê-lo noutros momentos."

Por fim, o conhecimento profundo da matéria de ensino foi apresentado pela professora como um fator determinante para o sucesso deste modelo, na medida em que o ensino dos conteúdos aos alunos que desempenharam a função de treinador, isto é, o que ensinar e como ensinar, exige um domínio mais aprofundado da matéria de ensino por parte da professora:

"Outro problema foi o fato de nunca ter lecionado Triplo Salto e há muito tempo que não abordava Barreiras o que me obrigou a estudar novamente e a investir na aquisição de conhecimentos e formas de abordagens destas duas especialidades do atletismo. É também essencial que se domine profundamente as matérias a lecionar, ainda para mais neste modelo pois tem que se transmitir de forma clara e objetiva os alunos que desempenharem a função de treinadores"

\section{DISCUSSÃO}

Este estudo examinou as perceções e, concomitantemente, os significados conferidos por uma professora de EF e os seus alunos à participação numa unidade de ensino de Atletismo balizada pelos preceitos pedagógicos e curriculares do MED. Em particular, pretendeuse compreender em que medida estes atores perceberam no MED o seu potencial educativo e de que modo os axiomas deste modelo, nomeadamente a competência, a literacia e o entusiasmo, podem ser desenvolvidos ao longo das aulas de Educação Física.

O clima de aprendizagem envolvente e a natureza particular do contexto embebidos no MED conferiram autenticidade e significado ampliados às práticas dos alunos, com impacto substancial na perceção dos participantes em relação aos três eixos invocados pelo MED, formar alunos desportivamente competentes, literatos e entusiastas (Siedentop et al, 2011). Neste âmbito, o desenvolvimento das tarefas em equipas capacitou os alunos enquanto decisores e construtores ativos do seu próprio processo de aprendizagem, incrementando a sua responsabilidade, a motivação para as práticas, o sentimento de pertença à equipa, o 
comprometimento para com a matéria de ensino e a prossecução dos objetivos de aprendizagem (MacPhail \& Kinchin, 2004; MacPhail et al., 2008; Kinchin, Wardle, Roderick \& Sprosen, 2004). A competência motora foi percebida como tendo sido desenvolvida devido: à responsabilidade assumida pelos alunos no desempenho dos seus papéis; ao compromisso coletivo para com a difusão da aprendizagem entre todos os membros da equipa e à extensão no tempo da unidade de ensino, com subsequente alargamento das oportunidades de aprendizagem. A literacia desportiva foi incrementada devido à cultura desportiva instalada ter potenciado uma conceção de competição reconfigurada, pela valorização do fair-play, pela viabilização do binómio inclusãocompetição e pela extensão das oportunidades de participação de todos os alunos nas atividades. Por sua vez, o incremento do entusiasmo pela prática desportiva foi percebido como resultante da autonomização dos alunos no desenvolvimento das tarefas de aprendizagem e na competição, bem como das características do contexto de aprendizagem (i.e., a afiliação e os elementos identificadores de pertença a uma equipa) associadas ao clima motivacional gerado no decorrer da temporada desportiva. Conforme advoga Hastie e Sinelnikov (2006) e Wallhead e Ntoumanis (2004) o MED dada a sua estrutura curricular e organizacional, potencia a criação de um clima de tarefa envolvente (do inglês, taskinvolving climate) que compromete solidamente os alunos com a matéria de ensino. Ademais, no presente estudo o gosto pela aprendizagem foi incrementado pelo investimento e significados que os praticantes atribuíram à ideia de pertencer a uma equipa. Em particular, uma consequência marcante deste processo foi o comprometimento dos alunos mais hábeis para com o ensino e monitorização dos colegas de menor nível de habilidade, uma condição frequentemente associada às dinâmicas operantes no trabalho cooperativo (Barret, 2005; Wallhead \& Ntoumanis, 2004). É de notar ainda que o clima de aprendizagem envolvente, embebido no trabalho cooperativo e nas tarefas de ensino entre pares, implicou uma reconfiguração do papel tradicional da professora e dos alunos no processo de ensino-aprendizagem, tendo estes assumido a 'posse do currículo' e a liderança de uma parcela significativa das tarefas instrucionais e gestão organizativa do espaço de aula. Tal convoca os alunos para o centro do processo, desafiando-os para a construção proativa da sua própria aprendizagem (Mesquita, 2012; Sinelnikov \& Hastie, 2008), catapultando a sua implicação (cognitiva e afetiva) no conteúdo das aprendizagens, aspeto que corrobora outros estudos (Dyson et al., 2004; Sinelnikov \& Hastie, 2008).

A perceção do incremento de competência desportiva dos alunos, relatada por estes e pela professora, corrobora outros estudos, tanto pelo exame das perceções dos alunos como dos professores (Coelho et al. 2012). No estudo de Coelho et al. (2012), as estratégias de ensino indireto e de responsabilização dos alunos foram percebidas pela professora como facilitadoras do entrelaçamento do sistema instrucional com o sistema social dos alunos, conferindo espaço ao debate e problematização das aprendizagens. Particularmente, a responsabilização dos alunos nas atividades desenvolvidas no seio de cada grupo foi percebida, pela professora, como crucial para o aumento dos seus níveis de participação e empenho, com reflexo na competência desportiva. Em concomitância, a capacidade de trabalho autónomo dos alunos, permitiu à professora mais espaço de intervenção no refinamento das aprendizagens, através de um trabalho mais individualizado, fator potenciador da competência desportiva dos alunos. Ademais, a perceção da melhoria de competência é confirmada pelo impacto do MED, nas aprendizagens dos alunos no Atletismo (Hastie et al. 2013; Pereira et al. 2013), na medida em que estes estudos relevam melhorias significativas na aprendizagem, mais concretamente na execução técnica, conhecimento e performance nas habilidades de lançamento do peso, triplo-salto e corrida de barreiras. Elencam-se como fatores cruciais para esta evidência, no presente estudo: a extensão alargada da unidade de ensino e do tempo disponível para a prática; a possibilidade de desempenho de papéis; e a natureza "saudável" da competição. De notar que, todos os alunos 
destacaram a duração prolongada da época desportiva de atletismo enquanto fator decisivo no processo de aprendizagem. De acordo com a investigação, o MED é particularmente atrativo quando confrontado com as tradicionais unidades de ensino curtas por viabilizar oportunidades acrescidas para jogar, competir e praticar com impacto decretório tanto na perceção de competência dos alunos (Hastie, 1998) como na avaliação efetiva da sua performance (Hastie, 1998; Hastie et al., 2009; Mesquita et al., 2012). Os alunos destacaram ainda que o desempenho de papéis diversificados proporcionou um espaço privilegiado para a aprendizagem dos conteúdos e das regras do Atletismo por meio da observação dos comportamentos motores dos colegas, reiterando estudos prévios (Hastie, 1998; Hastie, 1998; Hastie et al., 2009). Além disso, o desempenho de diferentes papéis (treinadores, juízes, etc.) incitou à inclusão de alunos, usualmente relegados para a periferia das atividades, pela possibilidade de permanecerem no centro das decisões em papéis que se estenderam ao de observadores e reguladores da prática (Hastie, 1998). Em particular, as raparigas e os alunos de menor nível de habilidade reconheceram sentirse úteis e contribuir para a equipa por meio do desempenho eficiente dos papéis desempenhados.

No referente ao papel cumprido pelos alunostreinadores, os colegas manifestaram a sua preferência pela participação em tarefas de ensino lideradas pelos pares, destacando o elevado compromisso dos seus treinadores para com os seus deveres enquanto líderes instrucionais. Hastie (2000) advoga que os alunos preferem a instrução liderada pelos colegas de equipa à dirigida pelos professores, na medida em que na condição de pares os treinadores integram o próprio sistema social dos alunos. Esta transferência de poder para os alunos favorece a interdependência entre o sistema social dos alunos, o sistema de tarefas de gestão (i.e., desempenho de papéis como árbitro, estatístico ou diretor desportivo) e o sistema de tarefas de instrução (i.e., no papel de treinadores) (Hastie, 2000; Mesquita et al., 2012). Em termos concretos, e no referente à prestação de contas (do inglês, accountability) por parte dos alunos, no decurso desta unidade de Atletismo, a sua performance foi maioritariamente percebida como estando relacionada com o seu nível de esforço, persistência e envolvimento pessoal nas tarefas, minimizando as perceções de competência com base na comparação entre os indivíduos (Sinelnikov \& Hastie, 2008).

Ademais, no presente estudo a presença sistemática da competição e a utilização de estratégias de ensino menos diretivas e menos centralizados no professor, em favor de atividades cooperativas e controladas pelos alunos, foram elementos curriculares influentes no incremento da perceção de competência dos alunos (Brunton, 2003); porquanto no MED o conceito de vencer transcende a ideia de simplesmente acumular mais pontos que o adversário (Perlman \& Karp, 2010). No presente estudo, os medidores de sucesso englobaram, não só a performance, mas simultaneamente a eficiência no desempenho dos papéis, os níveis de empenhamento e a concretização das premissas implícitas no conceito de fair play. Acrescenta-se ainda que, neste estudo, o enfoque na participação, esforço e comprometimento de todos os alunos para com as práticas, em detrimento do 'vencer a qualquer custo' parece ter fomentado um ambiente de aprendizagem que legitimou a participação equitativa de todos os alunos. Estes argumentos reforçam a importância de se promover um ambiente desportivo autêntico e inclusivo nas aulas de EF, no sentido de todos os alunos, independentemente do género e nível de habilidade, poderem contribuir para a equipa assegurando-se a sua integração e motivação para as práticas, premissa defendida pelo MED (Pill, 2008).

Um conjunto de considerações devem ser tecidas no tocante ao desenvolvimento profissional do professor de EF e ao potencial pedagógico do MED, emergentes deste estudo. $\mathrm{O}$ facto de este ter sido o primeiro contato da professora (embora experiente) com o MED, convoca a premência da intensificação do trabalho relacionado com a organização e planificação das atividades (Pill, 2008) e a necessidade dos professores patentearem um 
elevado conhecimento pedagógico do conteúdo, que lhes assegure capacidade adaptativa às dinâmicas curriculares do MED (Hastie \& Curtner-Smith, 2006). A investigação sublinha a resiliência de alguns professores em mudarem os seus hábitos de ensino (Ko, Wallhead, \& Ward, 2006; Pill, 2008) e, por outro, a visão do desafio de desenvolvimento profissional promovido pelo MED (Coelho et al., 2012). No presente estudo, o facto de a professora ter usufruído de um programa de formação sobre o ensino do MED (conforme referido na metodologia), pode ter sido determinante no desenvolvimento da sua capacidade em se ajustar às novas exigências instrucionais e, ainda, para a promoção da reflexão e desenvolvimento profissional, porquanto a docente foi convocada para desconstruir e reconstruir as suas crenças, experiências e conhecimentos em relação ao ato educativo. Este enunciado é concomitante com o preceituado por Alexander e Luckman (2001), os quais reforçam a ideia de que o MED representa não só um potencial de mudança de determinadas estruturas sociais presentes no ensino tradicional que constrangem as experiências desportivas de alguns alunos mas também um caminho para a renovação e reconstrução da identidade dos professores.

\section{CONCLUSÕES}

A vivência do MED numa unidade didática de Atletismo foi percebida tanto pelos alunos como pela professora como gratificante, do ponto de vista educativo, mormente pelo trabalho na aula ser concretizada numa perspetiva de aprendizagem cooperativa, tendo na competição o eixo nuclear da estruturação do processo de ensino-aprendizagem. A possibilidade de se desenvolver nos alunos os objetivos que subjazem concetualmente o MED, isto é, tornarem-se desportivamente cultos, literatos e entusiastas foi percebida pelos participantes, como resultante fundamentalmente dos sistemas de equidade e de coparticipação desenvolvidos e implementados pela professora, pela responsabilização e autonomização dos alunos no trabalho em equipa e pela valorização do fairplay. Ademais, a criação de oportunidades autênticas e substantivas de participação de todos os alunos sem exceção foi percebida como a razão maior que incitou nos alunos a vontade de se auto-superarem e, concomitantemente, adquirirem e desenvolverem competências motoras específicas do Atletismo.

Por sua vez, a experiência pedagógica da professora no ensino do Atletismo através do MED evidenciou ser de grande valor, porquanto incitou a mesma a rever os seus processos pedagógicos, a (re)construir estratégias otimizadoras do sucesso pedagógico do MED, particularmente na preparação dos alunos que desempenharam a função de treinadores e, ainda, na construção de materiais didáticos percursores do trabalho eficaz das equipas. A necessidade da professora se preparar pedagogicamente para a aplicação de uma abordagem de ensino centrada no aluno, quando a sua zona de conforto se pautava pela atuação na abordagem mais tradicional, isto é centrada no professor, foi decisiva para estimular a autorreflexão em torno da sua atuação pedagógica e, concomitantemente, contribuir para o seu desenvolvimento profissional sustentado.

Não obstante, a aplicação neste estudo de apenas uma unidade temática pode ser encarada como uma limitação, porquanto o exame minucioso do valor educativo de qualquer modelo requer tempo para que efetivamente se aceda aos pormenores que explicam os "porquês", os "como" e os "quandos"das decisões tomadas pelo professor e alunos. Deste modo, torna-se decisivo para a investigação futura, o recurso a desenhos de estudos mais extensivos no tempo e que incluam, não só, as representações dos atores mas, também, a observação participante no sentido de se aceder ao exame minucioso ao longo do tempo do processo de ensino-aprendizagem. Tal é o da investigação-ação, a qual permite a (des)construção e (re)construção das dinâmica inerentes as práticas pedagógicas e dos papéis dos atores que nela coabitam. Complementarmente, devem ser realizados estudos de caso, os quais, oferecem testemunhos de experiências pedagógicas de valor singular na implementação do MED, contribuindo de forma inequívoca para a melhoria das práticas 
profissionais, bem como para o refinamento da arquitetura e funcionalidade do modelo.

\begin{tabular}{l} 
Agradecimentos: \\
Nada a declarar \\
\hline
\end{tabular}

Conflito de Interesses:

Nada a declarar.

\section{Financiamento:}

Nada a declarar

\section{REFERÊNCIAS}

Alexander, K., \& Luckman, J. (2001). Australian teachers' perceptions and uses of the sport education curriculum model. European Physical Education Review, 7(3), 243-267.

Barrett, T. (2005). Effects of cooperative learning on the performance of sixth-grade physical education students. Journal of Teaching in Physical Education, 24(1), 88-102. Doi: 10.1123/jtpe.24.1.88

Bennett, G., \& Hastie, P. A. (1997). A sport education curriculum model for a collegiate physical activity course. Journal of Physical Education, Recreation and Dance, 68(1), 39-44. Doi: 10.1080/07303084.1997.10604876

Browne, T., Carlson, T., \& Hastie, P. A. (2004). A comparison of rugby seasons presented in traditional and sport education formats. European Physical Education Review, 10(2), 199-214.

Brunton, J. (2003). Changing hierarchies of power in physical education using sport education. European Physical Education Review, 9(3), 267284.

Coelho, I., Farias. C., Santos, D., Rolim, R., \& Mesquita, I. (2012). Ensinar e aprender o atletismo com o modelo de educação desportiva: Relatos de uma professora e dos seus alunos. Revista Portuguesa de Ciências do Desporto, 12(1), 13-30.

Curnow, J., \& Macdonald, D. (1995). Can sport education be gender inclusive: A case study in an upper primary school. ACHPER Healthy Lifestyles Journal, (150), 9-11.

Dyson, B., Griffin, L., \& Hastie, P. A. (2004). Sport education, tactical games, and cooperative learning: Theoretical and pedagogical considerations. Quest, 56(2), 226-240. doi: 10.1080/00336297.2004.10491823

Elo, S., \& Kyngäs, H. (2008). The qualitative content analysis process. Journal of Advanced Nursing, 62(1), 107-115.

Graça, A., \& Mesquita, I. (2003). Physical education teachers' conceptions about teaching TGfU in portuguese schools. In J. Butler, L. Griffin, B.
Lombard, \& R. Nastasi (Eds), Teaching Games for Understanding in Physical Education and Sport (pp. 87-97). United States of America: National Association for Sport and Physical Education.

Graça, A., \& Mesquita, I. (2009). Modelos de ensino dos jogos desportivos. In A. Rosado, \& I. Mesquita (Ed.), Pedagogia do Desporto (pp. 131163). Lisboa: FMH.

Grant, B. C. (1992). Integrating sport into the physical education curriculum in New Zealand secondary schools. Quest, 44(3), 304-316. doi: 10.1080/00336297.1992.10484057

Gratton, C., \& Jones, I. (2004). Research methods for sport studies. London: Routledge.

Hastie, P. A. (1998). The participation and perceptions of girls within a unit of sport education. Journal of Teaching in Physical Education, 17(2), 157171. doi: 10.1123/jtpe.17.2.157

Hastie, P. A. (1998). Skill and tactical development during a sport education season. Res $Q$ Exerc Sport, 69(4), 368-379.

Hastie, P. A. (2000). An ecological analysis of a sport education season. Journal of Teaching in Physical Education, 19(3), 355-373. doi: 10.1123/jtpe.19.3.355

Hastie, P. A. (2011). The nature and purpose of Sport Education as an educational experience. In $\mathrm{P}$. Hastie (Ed.), Sport education: International perspectives. Routledge Studies in Physical Education and Youth Sport (pp. 1-12). USA: Routledge.

Hastie, P. A., Calderón, A., Rolim, R., \& Guarino, A. J. (2013). The development of skill and knowledge during a sport education season of track and field athletics. Res Q Exerc Sport, 84(3), 336-344.

Hastie, P. A., Martinez, D. O., \& Calderón, A. (2011). A review of research on sport education: 2004 to the present. Physical Education and Sport Pedagogy, 16(2), 103-132.

Hastie, P. A., \& Sinelnikov, O. (2006). Russian students' participation in and perceptions of a season of Sport Education. European Physical Education Review, 12(2), 131-150.

Hastie, P. A., Sinelnikov, O., \& Guarino, A. J. (2009). The development of skill and tactical competencies during a season of badminton. European Journal of Sport Science, 9(3), 133140.

Hastie, P. A., Sluder, J. B., Buchanan, A. M., \& Wadsworth, D. D. (2009). The impact of an obstacle course sport education season on students' aerobic fitness levels. Res $Q$ Exerc Sport, 80(4), 788-791.

Hastie, P. A., \& Curtner-Smith, M. D. (2006). Influence of a hybrid sport education: Teaching games for understanding unit on one teacher and his students. Physical Education and Sport Pedagogy, 11(1), 1-27.

Kandola, D., Banner, D., O'Keefe-McCarthy, S., \& Jassal, D. (2014). Sampling methods in cardiovascular nursing research: An Overview. 
Canadian Journal of Cardiovascular Nursing, 24(3), 15-18.

Kinchin, G. D., Wardle, C., Roderick, S., \& Sprosen, A. (2004). A survey of year 9 boys' perceptions of sport education in one English secondary school. Bulletin of Physical Education, 40(1), 27-40.

Ko, B., Wallhead, T., \& Ward, P. (2006). Chapter 4: Professional development workshops: What do teachers learn and use? Journal of Teaching in Physical Education, 25(4), 397-412.

MacPhail, A., \& Kinchin, G. (2004). The use of drawings as an evalutive tool: students' experiences of Sport Education. Physical Education and Sport Pedagogy, 9(1), 86-108.

MacPhail, A., Gorely, T., Kirk, D., \& Kinchin, G. (2008). Children's experiences of fun and enjoyment during a season of sport education. Res Q Exerc Sport, 79(3), 344-355.

Mesquita, I. (2012). Fundar o lugar do desporto na escola através do modelo de educação desportiva. In I. Mesquita, \& J. Bento (Eds.), Professor de Educação Física: Fundar e dignificar a profissão (pp. 177-206). Belo Horizonte: Casa da Educação Física.

Mesquita, I. (2013). Perspectiva construtivista da aprendizagem no ensino do jogo. In J. V. d. Nascimento, V. Ramos \& F. Tavares (Eds.), Jogos Desportivos: formação e Investigação (Vol. 4). Florianópolis: UDESC.

Mesquita, I., Farias, C., \& Hastie, P. A. (2012). The impact of a hybrid sport education-invasion games competence model soccer unit on students' decision making, skill execution and overall game performance. European Physical Education Review, 18(2), 205-219.

Mesquita, I., \& Graça, A. (2009). Modelos instrucionais no ensino do desporto. In A. Rosado, \& I. Mesquita (Eds.). Pedagogia do Desporto (pp. 39-68). Lisboa: Edições FMHUTL.

Mesquita, I., Graça, A., Gomes, A. R., \& Cruz, C. (2005). Examining the impact of a step game approach to teaching volleyball on student tactical decision making and skill execution during game play. Journal of Human Movement Studies, 48(6), 469-492.

Metzler, M. (2005). Implications of models-based instruction for research on teaching: a focus on Teaching Games for Understanding. In: L. Griffin, \& J. Butler (Eds.), Teaching Games for Understanding: theory, research, and practice (pp. 183-197). Champaign, IL: Human Kinetics.
Miles, M., \& Huberman, M. (1994). Qualitative data analysis: An extended sourcebook. Michigan: SAGE.

Moraes, R. (1999). Análise de conteúdo. Revista Educação, 22(37), 7-32.

O'Donovan, T. M. (2003). A changing culture? Interrogating the dynamics of peer affiliations over the course of a season. European Physical Education Review, 9(3), 237-252.

Patton, M. Q. (1990). Qualitative Evaluation and Research Methods (2 ed.). Newbury Park: Sage.

Pereira, J., Mesquita, I., Araújo, R., \& Rolim, R. (2013). Estudo comparativo entre o Modelo de Educação Desportiva e o Modelo de Instrução Direta no enisno de habilidades técnico-motoras do Atletismo nas aulas de Educação Física. Revista Portuguesa de Ciências do Desporto, 13(2), 29-43.

Perkins, D. (1999). The many faces of constructivism. Alexandria: Educational Leadership

Perlman, D., \& Karp, G. G. (2010). A self-determined perspective of the sport education model. Physical Education and Sport Pedagogy, 15(4), 401-418.

Pill, S. (2008). A teachers' perceptions of the sport education model as an alternative for upper primary school physical education. Australian Council for Health, Physical Education, and Recreation Healthy Lifestyles Journal, 55(2/3), 23-29.

Siedentop, D. (1994). Sport Education: Quality PE through positive sport experiences. Champaingn, IL: Human Kinetics.

Siedentop, D., Hastie, P., \& Van der Mars, H. (2011). Complete guide to sport education ( $2^{\mathrm{a}}$ ed.). Champaign, IL: Human Kinetics.

Silverman, D. (2000). Doing qualitative research: $A$ practical handbook. London: SAGE.

Sinelnikov, O. A., \& Hastie, P. A. (2008). Teaching sport education to Russian students: An ecological analysis. European Physical Education Review, 14(2), 203-222.

Slavin, R. E. (1995). Cooperative Learning: Theory, research and practice (2 ed.). Boston: Allyn and Bacon.

Wallhead, T., \& Ntoumanis, N. (2004). Effects of a sport education intervention on students' motivational responses in physical education. Journal of Teaching in Physical Education, 23(1), 4-18. 